\title{
Wood ants protect their brood with tree resin
}

\author{
Timothée Brütsch*, Michel Chapuisat \\ Department of Ecology and Evolution, Biophore, UNIL-Sorge, University of Lausanne, Lausanne, Switzerland
}

\section{A R T I C L E I N F O}

\section{Article history:}

Received 22 November 2013

Initial acceptance 17 December 2013

Final acceptance 23 April 2014

Published online

MS. number: 13-00971R

\section{Keywords:}

ant

brood protection

Formica paralugubris

prophylaxis

resin

sanitation

self-medication

social immunity

social insects
Social insects use multiple lines of collective defences to combat pathogens. One example of a behavioural group defence is the use of antimicrobial plant compounds to disinfect the nest. Indeed, wood ants collect coniferous tree resin, and the presence of resin in their nest protects them against fungal and bacterial pathogens. Many questions remain on the mechanisms of resin use, including which factors elicit resin collection and placement within nests. Here, we investigated whether the presence of brood induces Formica paralugubris workers to collect more resin, and whether the workers preferentially place resin near the brood. We also tested whether the collection and placement of resin depends on the presence of the fungal entomopathogen Beauveria bassiana. Workers brought more resin to their nest when brood was present, and preferentially placed the resin near the brood. In contrast, workers did not increase resin collection in response to exposure to $B$. bassiana, nor did they place resin closer to contaminated brood or contaminated areas of the nest. This lack of response may be explained by a limited effect of resin against the germination and growth of $B$. bassiana in vitro. Overall, our main result is that woods ants actively position resin near the brood, which probably confers prophylactic protection against other detrimental microorganisms.

(c) 2014 The Association for the Study of Animal Behaviour. Published by Elsevier Ltd. All rights reserved.
The use of plant compounds to combat parasites has been documented in various animal taxa, including insects, birds and mammals (Chapuisat, Oppliger, Magliano, \& Christe, 2007; Clayton \& Wolfe, 1993; Lefèvre, Oliver, Hunter, \& de Roode, 2010; Simone, Evans, \& Spivak, 2009). The mechanisms are also varied, from direct ingestion and topical application to nest fumigation (Gwinner \& Berger, 2006; Huffman, 2003; Villalba, Provenza, \& Shaw, 2006). Plant use may be prophylactic or curative, and may benefit the individual or its offspring (de Roode, Lefèvre, \& Hunter, 2013). For example, monarch butterflies preferentially lay eggs on toxic plants when they are infected by protozoan parasites, which reduces the growth of the parasite in their offspring (Lefèvre et al., 2010, 2012). However, in many cases the mechanisms governing the use of medicinal substances by animals are still poorly known, and it is notably difficult to demonstrate that the contact with the substance is deliberate and primarily aimed at fighting parasites (Clayton \& Wolfe, 1993; Gwinner \& Berger, 2005; Manson, Otterstatter, \& Thomson, 2010; Suárez-Rodríguez, López-Rull, \& Garcia, 2013).

In social insects, many defences are collective and contribute to diminish the parasite pressure at the colony level (Cremer,

\footnotetext{
* Correspondence: T. Brütsch, Department of Ecology and Evolution, Biophore, UNIL-Sorge, University of Lausanne, 1015 Lausanne, Switzerland.

E-mail address: timothee.brutsch@unil.ch (T. Brütsch).
}

Armitage, \& Schmid-Hempel, 2007; de Roode \& Lefèvre, 2012; Wilson-Rich, Spivak, Fefferman, \& Starks, 2009). The use of medicinal plant substances has been primarily documented in wood ants and bees (Chapuisat et al., 2007; Christe, Oppliger, Bancala, Castella, \& Chapuisat, 2003; Simone-Finstrom \& Spivak, 2010). Indeed, wood ants, honeybees and stingless bees collect and incorporate plant resin into their nests (Christe et al., 2003; Duangphakdee, Koeniger, Deowanish, Hepburn, \& Wongsiri, 2009; Simone et al., 2009). Owing to its antifungal and antibacterial properties, this resin may protect the colony against multiple pathogens (Banskota, Tezuka, \& Kadota, 2001; Chapuisat et al., 2007; Christe et al., 2003; Simone-Finstrom \& Spivak, 2010). For example, in the wood ant Formica paralugubris, the presence of resin increased the survival of adult workers and larvae exposed to the bacteria Pseudomonas fluorescens, as well as the survival of larvae exposed to the fungal pathogen Metarhizium anisopliae (Chapuisat et al., 2007). Moreover, in wood ants and honeybees, the presence of resin reduced the microbial load and allowed individuals to downregulate some components of their immune system (Castella, Chapuisat, Moret, \& Christe, 2008; Christe et al., 2003; Simone et al., 2009).

The mechanisms governing the use of resin by wood ants remain little known. Field experiments revealed that workers foraging on trails prefer to collect resin over other kinds of nest material, such as twigs and small stones (Castella, Christe, \& 
Chapuisat, 2008). The preference for resin was higher in spring and summer than in autumn, raising the hypothesis that resin collection might primarily serve to protect the brood, which is produced at this time of the year (Castella, Christe, et al., 2008).

Laboratory experiments also suggested that the use of resin was prophylactic and constitutive rather than curative and infectiondependent, as the workers did not increase resin collection when their colonies were exposed to M. anisopliae (Castella, Christe, et al., 2008). However, the behavioural response may depend on the parasite. For example, honeybee colonies tended to increase resin collection after being challenged with the fungal pathogen Ascosphaera apis (Simone-Finstrom \& Spivak, 2012). Hence, more fungal pathogens should be tested in wood ants. Moreover, the hypothesis that workers preferentially place the resin close to contaminated brood or contaminated nest areas, compared with uncontaminated ones, has not been tested so far.

Here, we investigated whether the presence of brood and/or of the virulent fungal entomopathogen Beauveria bassiana influences the rate of resin collection by wood ant workers, as well as the spatial distribution of resin in the nests. If $F$. paralugubris workers use resin to protect brood, we expected that they would collect more resin when brood was present in their nest, and that they would place the resin close to the brood. If the ants use resin in response to the fungal contamination rather than as a constitutive prophylaxis, we expected workers to increase resin collection after exposure to $B$. bassiana, and to preferentially place resin near contaminated brood or contaminated nest areas.

\section{METHODS}

In our experiment, workers collected resin from foraging arenas and placed it in experimental nests (Fig. 1). We sampled

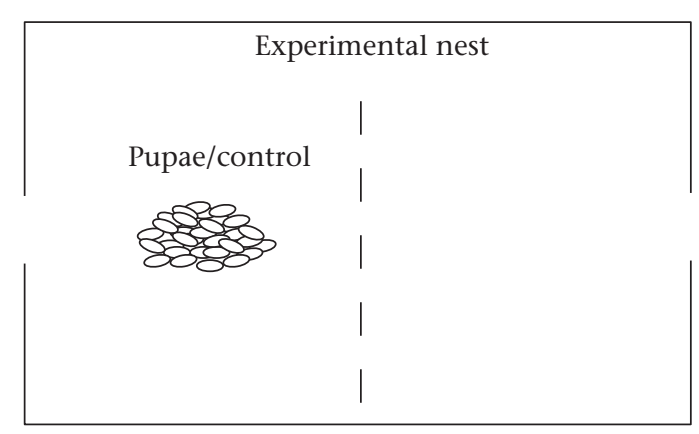

Foraging arena

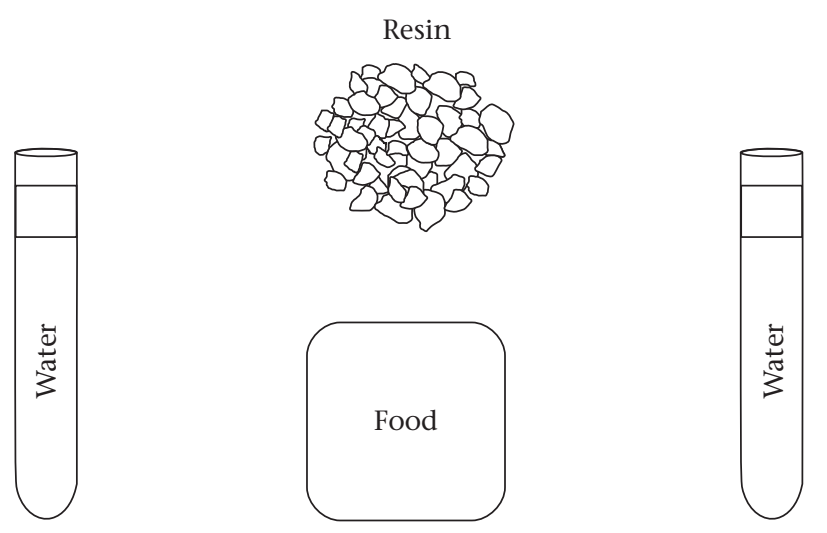

Figure 1. Outline of the experimental set-up. The dashed line indicates the internal separation of the nest material into two compartments. See Methods for details.
F. paralugubris workers, brood and nest material from 20 field nests in the 'Chalet à Roch' population. The study population is located in sparse spruce forest (Asplenio - Piceetum) at an altitude between 1320 and $1420 \mathrm{~m}$ in the Swiss Jura mountains (Cherix, 1980). It consists of hundreds of large and highly polygynous nests interconnected by trails and forming a supercolony (Chapuisat, Goudet, \& Keller, 1997; Holzer, Chapuisat, Kremer, Finet, \& Keller, 2006). The sampled brood consisted of pupae, which are abundant and easy to sample in the upper parts of mounds. Because of their soft cuticles, ant pupae tend to be highly susceptible to fungal entomopathogens (Tragust, Ugelvig, Chapuisat, Heinze, \& Cremer, 2013).

In the laboratory, we removed the resin already present in the nest material. We split the samples from each field nest into four experimental nests, assigned to four treatments, in full factorial design: presence or absence of pupae and presence or absence of B. bassiana, a virulent generalist fungal entomopathogen (Uma Devi, Padmavathi, Uma Maheswara Rao, Khan, \& Mohan, 2008). Beauveria bassiana has been reported to successfully infect and kill adult ant workers (Purcell, Brütsch, \& Chapuisat, 2012; Reber \& Chapuisat, 2012a) and brood (Broome, Sikorowski, \& Norment, 1976; Patterson, Briano, Wildey, \& Robinson, 1993).

To monitor the spatial distribution of resin, each experimental nest had two internal compartments, one that received nest material with pupae and/or parasite contamination, while the other received only nest material (Fig. 1 ). The nest consisted of a dark plastic box $(13.8 \times 18.3 \mathrm{~cm}$ and $6.2 \mathrm{~cm}$ high $)$ filled with resin-free nest material up to a height of $1.5-2 \mathrm{~cm}$. The two equal-sized internal compartments were separated by a thin wall of plastic $3.5 \mathrm{~cm}$ high that divided nest material but did not reach the top of the box, so that the ants could easily move between compartments inside the nest. Each compartment had a small entrance hole giving way to a foraging arena consisting of a plastic tray $(22 \times 35 \mathrm{~cm}$ and $15 \mathrm{~cm}$ high) lined with Fluon to prevent ants from escaping. Each experimental nest received 200 workers.

In the foraging arena, the workers had access to $2.5 \mathrm{~g}$ of coniferous tree resin, in the form of approximately 300 grains of resin of various sizes that were previously removed from the nest material. Workers also had ad libitum access to water and standard jelly food (Reber \& Chapuisat, 2012b).

For each of the 20 field nests, one of the four experimental nests received one of the four following experimental treatments.

(1) Presence of uncontaminated brood (Brood +, Pathogen -). We placed 100 pupae originating from the same field nest as the workers in one randomly chosen compartment of the nest. The group of pupae had been sprayed with approximately $220 \mu \mathrm{l}$ of control solution $(0.05 \%$ sterile Tween 20$)$.

(2) Presence of uncontaminated control items (Brood -, Pathogen -). One of the nest compartments received 100 small plastic pieces similar to pupae in size and shape (approximately $4 \mathrm{~mm}$ long and $3 \mathrm{~mm}$ wide). These pieces had been sprayed with control solution.

(3) Presence of brood contaminated by the fungal pathogen (Brood + , Pathogen + ). One of the nest compartments received 100 pupae that had been sprayed with approximately $220 \mu \mathrm{l}$ of $B$. bassiana spore solution $\left(4.6 \times 10^{7}\right.$ conidia $\left./ \mathrm{ml}\right)$.

(4) Presence of control items contaminated by the fungal pathogen (Brood -, Pathogen + ). One of the nest compartments received 100 small plastic pieces that had been sprayed with B. bassiana spore solution.

We checked the content of the experimental nests on a daily basis, recording the position of brood or control plastic pieces. In three cases, the workers transferred all the brood to the opposite compartment towards the end of the experiment. We conservatively kept these nests and their original brood compartment in the analyses. However, we checked that excluding these three nests or 
redefining their brood compartments did not affect the outcomes of the statistical tests. After 1 week, we weighed the total amount of resin that the ants had placed in each compartment of each nest. At the end of the experiment, the workers were euthanized in $\mathrm{a}-20^{\circ} \mathrm{C}$ freezer.

In follow-up experiments aiming at further distinguishing between a constitutive and therapeutic use of resin, we assessed whether the resin inhibited the germination and growth of B. bassiana in vitro. We performed two types of growth inhibition assays. First, we spread $100 \mu \mathrm{l}$ of a spore solution $\left(10^{7}\right.$ spores per ml in $0.05 \%$ Tween 20 ) on $9 \mathrm{~cm}$ diameter petri dishes containing malt extract agar (MEA). We placed four pieces of resin on each petri dish (e.g. Chapuisat et al., 2007). Second, we performed well diffusion assays, adapted from Mandeel and Taha (2005). In petri dishes, we mixed spores with MEA, using three final concentrations: $2 \times 10^{6}, 6 \times 10^{5}$ and $10^{4}$ spores per ml, respectively. In each plate, we cut four $4 \mathrm{~mm}$ diameter holes. Two of these holes were filled with resin dissolved in ethanol (100\% mass/volume). One of the remaining two holes was filled with ethanol, as a negative control, while the other was filled with $14 \%$ bleach, a potent, broadspectrum antifungal substance, as a positive control. We incubated the plates at $25^{\circ} \mathrm{C}$ for 4 days.

\section{Statistical Analyses}

To test whether the presence of pupae, the exposure to the pathogen or an interaction between the two factors influenced the total amount of resin that workers brought to the nest, we constructed a mixed-effect model with pupae presence and exposure to the pathogen as fixed factors, and the field nest as a random factor, using the lmer function (Bates, Maechler, Bolker, \& Walker, 2013) in $R$ version 3.0.2 ( $R$ Development Core Team, 2013). We obtained $P$ values from likelihood ratio tests comparing models with and without the variable of interest.

To examine whether the workers preferentially deposited the resin near the brood and/or the fungal pathogen, we compared the amount of resin in the compartment containing pupae and/or pathogen with that in the compartment containing only nest material. We used paired-sample Welch $t$ tests, as the compartments are paired within each experimental nest.

\section{RESULTS}

Workers brought significantly more resin to the nest in the presence of pupae than in control, broodless conditions (Fig. 2a; $\left.\chi_{1}^{2}=12.2, P=0.0005\right)$. In contrast, workers did not change their rate of resin collection when the pupae or control plastic pieces were contaminated with pathogenic $B$. bassiana spores $\left(\chi_{1}^{2}=0.36\right.$, $P=0.55)$. There was no significant interaction between the presence of pupae and the exposure to the pathogen, which indicates that the impact of brood presence on resin collection is independent of fungal contamination $\left(\chi_{1}^{2}=0.18, P=0.67\right)$.

Within experimental nests, workers preferentially placed the resin near pupae, independently of the fungal contamination. Indeed, the mass of resin was significantly higher in the compartments containing uncontaminated pupae (paired-samples Welch $t$ test: $t_{19}=3.3, P=0.003$ ) or in the compartments containing Beauveria-contaminated pupae $\left(t_{19}=2.6, P=0.02\right)$ than in the corresponding broodless compartments of the same experimental nests (Fig. 2b). In contrast, workers did not place more resin in compartments with control plastic pieces $\left(t_{19}=1.1, P=0.28\right)$ or in compartments with Beauveria-contaminated plastic pieces $\left(t_{19}=-0.22, P=0.83\right)$ than in the broodless compartments of the same experimental nests (Fig. 2b). Usually, the resin tended to be distributed evenly in the compartment containing the brood.
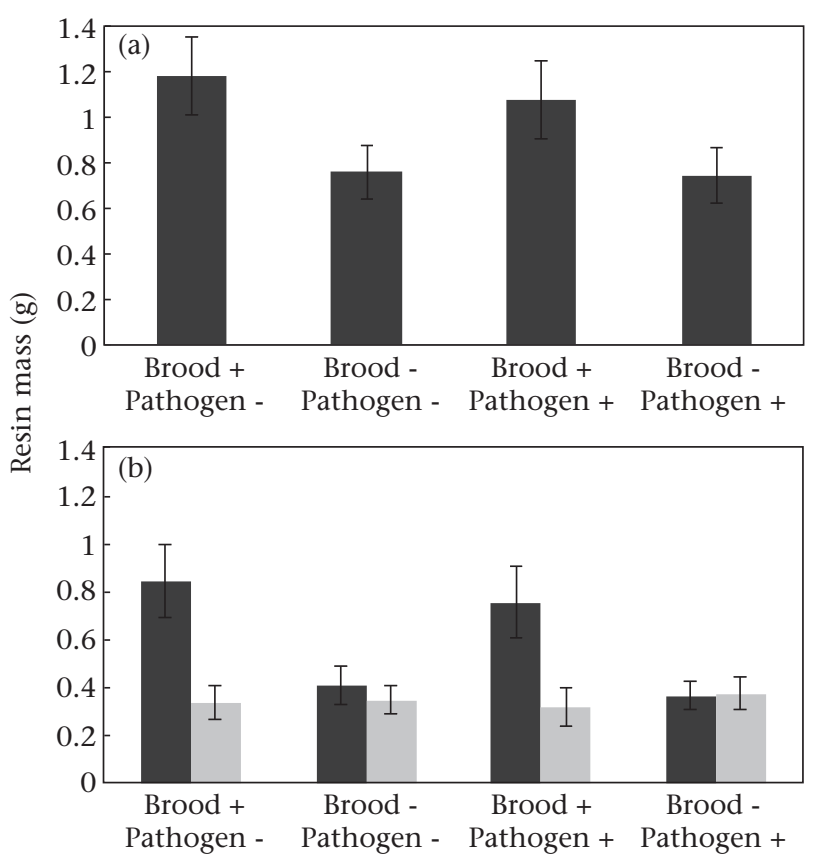

Figure 2. (a) Average total amount of resin that wood ant workers brought to the experimental nests and (b) average amount of resin that wood ant workers brought into each nest compartment, as a function of brood presence and exposure to the fungal pathogen $B$. bassiana. Each nest had two compartments, of which one, randomly chosen, received the treatment. In (b), black and grey bars show the average amount of resin placed in treated compartments and in compartments that contained only nest material, respectively. Brood $+/$ - indicates pupae presence/absence, and pathogen +1 - pathogen presence/absence, respectively. Sample size was 20 experimental nests per treatment. Error bars indicate standard error of the mean quantity of resin collected.

However, in one uncontaminated nest, the resin was clearly placed around the pupae.

In the follow-up experiments testing the effect of resin against B. bassiana in vitro, we did not observe distinctive inhibition halos around the pieces of resin, nor around the wells filled with resin dissolved in ethanol. We observed large fungus-free halos around the wells containing bleach, but not around those containing only ethanol. This suggests that the resin has little effect against the germination and growth of $B$. bassiana, at least in the conditions tested.

\section{DISCUSSION}

Wood ant workers collected significantly more tree resin when brood was present in their nests. Specifically, the presence of pupae in experimental nests led workers to bring $50 \%$ more resin from the foraging arenas to the nests, compared with the broodless situation. Moreover, within the nests, workers preferentially placed the resin near pupae. On average, $71 \%$ of the resin collected by workers was placed in the nest compartment containing brood; the rest was deposited in the compartment containing only nest material.

The experimental findings that workers retrieve more resin when pupae are present in their nest and that they preferentially place the resin near pupae strongly support the hypothesis that workers use resin to protect their brood from pathogens. This is in line with earlier findings showing that the presence of resin decreases the prevalence of bacteria and fungi in nest material (Christe et al., 2003), and protects the larvae against some specific virulent bacterial and fungal pathogens (Chapuisat et al., 2007). A higher rate of resin collection when brood is present is also fully consistent with the field observation that workers collect 
proportionally more resin in spring and summer, when brood is produced, than in autumn (Castella, Christe, et al., 2008).

In the social insects, brood is of crucial importance for the future of the colony, and often receives extra protection (Ayasse \& Paxton, 2002; Cremer et al., 2007). The brood is likely to be particularly sensitive to pathogens, because larvae and pupae do not have a fully sclerotized and melanized cuticle, which facilitates the penetration of fungal spores (Ortiz-Urquiza \& Keyhani, 2013). The brood also lacks some of the antibiotic-producing glands of adult ants, such as metapleural glands (Stow \& Beattie, 2008).

Many behavioural defences seem to be targeted at brood protection against pathogens. Some ants preventively self-groom before entering the brood chamber (Morelos-Juárez, Walker, Lopes, \& Hughes, 2010), while others stay away from brood when they are contaminated (Ugelvig \& Cremer, 2007). Some ants even place venom on fungus-exposed brood to disinfect them (Tragust, Mitteregger, et al., 2013). The maintenance of a strict nest hygiene, removal of diseased individuals and allogrooming of all individuals returning to the colony are also efficient but less specific ways to prevent the spread of diseases (Hart \& Ratnieks, 2002; Reber, Purcell, Buechel, Buri, \& Chapuisat, 2011; Tragust, Ugelvig, et al., 2013; Wilson-Rich et al., 2009). Given the strong and broad-spectrum antimicrobial activity of resin (Banskota et al., 2001; Chapuisat et al., 2007; Christe et al., 2003), depositing resin near brood appears to be another powerful measure to reduce the risk of infection in brood.

In our experiment, workers did not increase resin collection when the brood had been exposed to B. bassiana, nor did they place resin closer to contaminated brood or contaminated areas of the nest. There are several possible explanations for this lack of response. First, resin may have little effect against $B$. bassiana. In line with this hypothesis, in our follow-up assay in vitro the resin did not inhibit the germination and growth of the pathogen. Second, $B$. bassiana may have only limited impact on ant pupae in natural conditions, for example due to cocoon presence or systematic allogrooming (Reber et al., 2011; Tragust, Ugelvig, et al., 2013). Third, workers may not be able to detect the presence of spores or of infected pupae. In our experiment, we did not detect any removal of contaminated or dead pupae from the nests.

Overall, our experiment suggests that resin collection is constitutive and prophylactic, as it does not depend on the presence of specific pathogens. These results are similar to those obtained when these ants were challenged with another generalist fungal entomopathogen, $M$. anisopliae, which, in contrast to $B$. bassiana, was inhibited by resin and detrimental to the ants (Castella, Christe, et al., 2008; Chapuisat et al., 2007). Prophylactic defences are often perceived as fixed, whereas therapeutic defences are seen as plastic, varying with the risk and predictability of infection (de Roode \& Lefèvre, 2012). Here, we have shown that resin collection and placement is both prophylactic and plastic, as it depends on the presence of brood in the nest.

Although a prophylactic, multitarget use of resin is probably common, a therapeutic response might still occur to fight more specific pathogens, as has been documented in the honeybee (Simone-Finstrom \& Spivak, 2012). Conditional, adaptive responses to endoparasite infections have also been reported in monarch butterflies, which lay eggs on toxic plants (Lefèvre et al., 2010, 2012), and fruit fly larvae, which increase ethanol consumption (Milan, Kacsoh, \& Schlenke, 2012).

In conclusion, wood ants brought more resin to their nests when brood was present, and they deposited the resin near the brood, independently of the presence of a fungal pathogen. When combined with our previous findings on the protective effects of resin (Chapuisat et al., 2007; Christe et al., 2003), these new results indicate that wood ants actively place resin near the brood in order to prophylactically protect these vulnerable and valuable colony members from detrimental microorganisms.

\section{Acknowledgments}

We thank Antoine Felden for help in the field and laboratory and Jessica Purcell, Raphaël Jeanson and three anonymous referees for helpful comments on the manuscript. The study was supported by grant 31003A_125306 from the Swiss National Science Foundation to M.C.

\section{References}

Ayasse, M., \& Paxton, R. J. (2002). Brood protection in social insects. In M. Hilker, \& T. Meiners (Eds.), Chemoecology of insect eggs and egg deposition (pp. 117-148). Berlin: Blackwell.

Banskota, A. H., Tezuka, Y., \& Kadota, S. (2001). Recent progress in pharmacological research of propolis. Phytotherapy Research, 15(7), 561-571.

Bates, D., Maechler, M., Bolker, B., \& Walker, S. (2013). Ime4: Linear mixed-effects models using Eigen and S4. R package version 1.0-5 http://CRAN.R-project.org package $=$ lme 4 .

Broome, J. R., Sikorowski, P. P., \& Norment, B. R. (1976). A mechanism of pathogenicity of Beauveria bassiana on larvae of the imported fire ant, Solenopsis richteri. Journal of Invertebrate Pathology, 28(1), 87-91.

Castella, G., Chapuisat, M., Moret, Y., \& Christe, P. (2008). The presence of conifer resin decreases the use of the immune system in wood ants. Ecological Entomology, 33(3), 408-412.

Castella, G., Christe, P., \& Chapuisat, M. (2008). Prophylaxis with resin in wood ants. Animal Behaviour, 75(4), 1591-1596.

Chapuisat, M., Goudet, J., \& Keller, L. (1997). Microsatellites reveal high population viscosity and limited dispersal in the ant Formica paralugubris. Evolution, 51(2), 475-482.

Chapuisat, M., Oppliger, A., Magliano, P., \& Christe, P. (2007). Wood ants use resin to protect themselves against pathogens. Proceedings of the Royal Society B: Biological Sciences, 274(1621), 2013-2017.

Cherix, D. (1980). Note préliminaire sur la structure, la phénologie et le régime alimentaire d'une super-colonie de Formica lugubris zett. Insectes Sociaux, 27(3), 226-236.

Christe, P., Oppliger, A., Bancala, F., Castella, G., \& Chapuisat, M. (2003). Evidence for collective medication in ants. Ecology Letters, 6(1), 19-22.

Clayton, D. H., \& Wolfe, N. D. (1993). The adaptive significance of self-medication. Trends in Ecology \& Evolution, 8(2), 60-63.

Cremer, S., Armitage, S. A. O., \& Schmid-Hempel, P. (2007). Social immunity. Current Biology, 17(16), R693-R702.

Duangphakdee, O., Koeniger, N., Deowanish, S., Hepburn, H. R., \& Wongsiri, S. (2009). Ant repellent resins of honeybees and stingless bees. Insectes Sociaux, 56(4), 333-339.

Gwinner, H., \& Berger, S. (2005). European starlings: nestling condition, parasites and green nest material during the breeding season. Journal of Ornithology, 146(4), 365-371.

Gwinner, H., \& Berger, S. (2006). Parasite defence in birds: the role of volatiles. Acta Zoologica Sinica, 52, 280-283.

Hart, A. G., \& Ratnieks, F. L. W. (2002). Waste management in the leaf-cutting ant Atta colombica. Behavioral Ecology, 13(2), 224-231.

Holzer, B., Chapuisat, M., Kremer, N., Finet, C., \& Keller, L. (2006). Unicoloniality, recognition and genetic differentiation in a native Formica ant. Journal of Evolutionary Biology, 19(6), 2031-2039.

Huffman, M. A. (2003). Animal self-medication and ethno-medicine: exploration and exploitation of the medicinal properties of plants. Proceedings of the Nutrition Society, 62(02), 371-381.

Lefèvre, T., Chiang, A., Kelavkar, M., Li, H., Li, J., de Castillejo, C. L. F., et al. (2012). Behavioural resistance against a protozoan parasite in the monarch butterfly. Journal of Animal Ecology, 81(1), 70-79.

Lefèvre, T., Oliver, L., Hunter, M. D., \& de Roode, J. C. (2010). Evidence for transgenerational medication in nature. Ecology Letters, 13(12), 1485-1493.

Mandeel, Q., \& Taha, A. (2005). Assessment of in vitro antifungal activities of various extracts of indigenous Bahraini medicinal plants. Pharmaceutical Biology, 43(2), $164-172$.

Manson, J. S., Otterstatter, M. C., \& Thomson, J. D. (2010). Consumption of a nectar alkaloid reduces pathogen load in bumble bees. Oecologia, 162(1), 81-89.

Milan, N. F., Kacsoh, B. Z., \& Schlenke, T. A. (2012). Alcohol consumption as selfmedication against blood-borne parasites in the fruit fly. Current Biology, 22, $1-6$.

Morelos-Juárez, C., Walker, T. N., Lopes, J. F. S., \& Hughes, W. O. H. (2010). Ant farmers practice proactive personal hygiene to protect their fungus crop. Current Biology, 20(13), R553-R554.

Ortiz-Urquiza, A., \& Keyhani, N. O. (2013). Action on the surface: entomopathogenic fungi versus the insect cuticle. Insects, 4(3), 357-374.

Patterson, R. S., Briano, J. A., Wildey, K. B., \& Robinson, W. H. (1993, June). Potential of three biological control agents for suppression of Solenopsis invicta, the red 
imported fire ant. In Proceedings of the 1st international conference on insect pests in the urban environment (Vol. 498); (pp. 35-43). Exeter: BPCC Wheatons Ltd.

Purcell, J., Brütsch, T., \& Chapuisat, M. (2012). Effects of the social environment on the survival and fungal resistance of ant brood. Behavioral Ecology and Sociobiology, 66(3), 467-474.

R Development Core Team. (2013). R: A language and environment for statistical computing. Vienna, Austria: R Foundation for Statistical Computing. http:// www.R-project.org.

Reber, A., \& Chapuisat, M. (2012a). Diversity, prevalence and virulence of funga entomopathogens in colonies of the ant Formica selysi. Insectes Sociaux, 59(2), 231-239.

Reber, A., \& Chapuisat, M. (2012b). No evidence for immune priming in ants exposed to a fungal pathogen. PLoS One, 7(4), e35372.

Reber, A., Purcell, J., Buechel, S. D., Buri, P., \& Chapuisat, M. (2011). The expression and impact of antifungal grooming in ants. Journal of Evolutionary Biology, 24(5), 954-964.

de Roode, J. C., \& Lefèvre, T. (2012). Behavioral immunity in insects. Insects, 3(4) $789-820$.

de Roode, J. C., Lefèvre, T., \& Hunter, M. D. (2013). Self-medication in animals. Science, 340(6129), 150-151.

Simone, M., Evans, J. D., \& Spivak, M. (2009). Resin collection and social immunity in honey bees. Evolution, 63(11), 3016-3022.

Simone-Finstrom, M. D., \& Spivak, M. (2010). Propolis and bee health: the natural history and significance of resin use by honey bees. Apidologie, 41(3) 295-311.
Simone-Finstrom, M. D., \& Spivak, M. (2012). Increased resin collection after parasite challenge: a case of self-medication in honey bees? PLoS One, 7(3), e34601.

Stow, A., \& Beattie, A. J. (2008). Chemical and genetic defenses against disease in insect societies. Brain, Behavior, and Immunity, 22(7), 1009-1013.

Suárez-Rodríguez, M., López-Rull, I., \& Garcia, C. M. (2013). Incorporation of cigarette butts into nests reduces nest ectoparasite load in urban birds: new ingredients for an old recipe? Biology Letters, 9(1), 20120931.

Tragust, S., Mitteregger, B., Barone, V., Konrad, M., Ugelvig, L. V.. \& Cremer, S. (2013). Ants disinfect fungus-exposed brood by oral uptake and spread of their poison. Current Biology, 23(1), 76-82.

Tragust, S., Ugelvig, L. V., Chapuisat, M., Heinze, J., \& Cremer, S. (2013). Pupal cocoons affect sanitary brood care and limit fungal infections in ant colonies. BMC Evolutionary Biology, 13(1), 225.

Ugelvig, L. V., \& Cremer, S. (2007). Social prophylaxis: group interaction promotes collective immunity in ant colonies. Current Biology, 17(22), 1967-1971.

Uma Devi, K., Padmavathi, J., Uma Maheswara Rao, C., Khan, A. A. P., \& Mohan, M. C. (2008). A study of host specificity in the entomopathogenic fungus Beauveria bassiana (Hypocreales, Clavicipitaceae). Biocontrol Science and Technology, 18(10), 975-989.

Villalba, J. J., Provenza, F. D., \& Shaw, R. (2006). Sheep self-medicate when challenged with illness-inducing foods. Animal Behaviour, 71(5), 1131-1139.

Wilson-Rich, N., Spivak, M., Fefferman, N. H., \& Starks, P. T. (2009). Genetic, individual, and group facilitation of disease resistance in insect societies. Annual Review of Entomology, 54, 405-423. 